\title{
Aberrant maturation of mutant perforin underlies the clinical diversity of hemophagocytic lymphohistiocytosis
}

\author{
Kimberly A. Risma, ${ }^{1}$ Robert W. Frayer, ${ }^{2}$ Alexandra H. Filipovich, ${ }^{1,2}$ and Janos Sumegi \\ 1Division of Allergy/Immunology and 2Division of Hematology/Oncology, Cincinnati Children's Hospital Medical Center, \\ Department of Pediatrics, University of Cincinnati College of Medicine, Cincinnati, Ohio, USA.
}

\begin{abstract}
Missense mutations in perforin, a critical effector of lymphocyte cytotoxicity, lead to a spectrum of diseases, from familial hemophagocytic lymphohistiocytosis to an increased risk of tumorigenesis. Understanding of the impact of mutations has been limited by an inability to express human perforin in vitro. We have shown, for the first time to our knowledge, that recombinant human perforin is expressed, processed appropriately, and functional in rat basophilic leukemia (RBL) cells following retroviral transduction. Subsequently, we have addressed how perforin missense mutations lead to absent perforin detection and impaired cytotoxicity by analyzing $\mathbf{2 1}$ missense mutations by flow cytometry, immunohistochemistry, and immunoblot. We identified perforin missense mutations with partial maturation (class 1 ), no apparent proteolytic maturation (class 2), and no recognizable forms of perforin (class 3). Class 1 mutations exhibit lytic function when expressed in RBL cells and are associated with residual protein detection and variable cytotoxic function in affected individuals, suggesting that carriers of class 1 alleles may exhibit more subtle immune defects. By contrast, class 3 mutations cause severely diminished perforin detection and cytotoxicity, while class 2 mutations have an intermediate phenotype. Thus, the pathologic mechanism of perforin missense mutation likely involves a protein dosage effect of the mature protein.
\end{abstract}

\section{Introduction}

Perforin is a critical effector molecule of lymphocyte cytotoxicity, involved in the innate and adaptive immune response (1). NK cells express perforin constitutively, allowing the host to rapidly kill virus-infected and tumor-derived host cells. CTL cells upregulate perforin expression after TCR activation and thus emerge as effectors of adaptive immunity.

In mice in which the perforin gene has been disrupted, severe immune dysregulation occurs in response to lymphocytic choriomeningitis virus (LCMV) infection, due to an absence of perforin-mediated cytotoxicity (2-6). In contrast to WT mice, which normally clear LCMV infection, perforin knockout mice develop excessive activation and proliferation of $\mathrm{T}$ cells and macrophages, resulting in hemophagocytosis, systemic hypercytokinemia, and death. There is failure to eliminate viral infection and failure to resolve the excessive immune response.

In humans, perforin deficiency leads to a potentially fatal disorder in infancy, familial hemophagocytic lymphohistiocytosis type 2 (FHLH2) (7-16). FHLH2 is inherited as an autosomal recessive disorder, with mutations identified in the perforin coding sequence. Patients with mutations in the perforin gene (PRF1) have absent or low perforin levels in NK cells and diminished lymphocyte cytotoxicity. The mechanism for hemophagocytosis is thought to be analogous to that in the mouse model, with triggers such as EBV, CMV, and other viruses. The disease

Nonstandard abbreviations used: CMA, concanamycin A; FC, flow cytometry; FHLH2, familial hemophagocytic lymphohistiocytosis type 2; HLH, hemophagocytic lymphohistiocytosis; MCF, mean channel fluorescence; $P R F 1$, perforin gene; RBL, rat basophilic leukemia; TNP, trinitrophenyl.

Conflict of interest: The authors have declared that no conflict of interest exists.

Citation for this article: J. Clin. Invest. 116:182-192 (2006)

doi:10.1172/JCI26217. is fatal unless treated with immune suppression and ultimately bone marrow transplantation (17).

Several investigators have described older children and adults with FHLH2, with residual perforin expression and/or NK function, suggesting that the clinical spectrum of FHLH2 may be broader than originally described $(18,19)$. Missense mutations in PRF1 have also been described in an adult with chronic active EBV infection (20), in children and adults with bone marrow malignancies $(21,22)$, and in healthy individuals (23). These data suggest that the phenotypic expression of PRF1 mutations is variable, and that the spectrum of perforin-related disease may include fatal immune dysregulation in early childhood; nonfatal, inflammatory reactions at any age; and impaired tumor surveillance in children and adults.

Although perforin was identified over 20 years ago $(24,25)$, very little is known about its structure and function in the cytotoxic granule and upon release from the cell. In vitro studies of recombinant human perforin have been limited by an inability to express the human protein in a relevant cell line $(26,27)$. Murine perforin has been expressed in a rat basophilic leukemia (RBL) mast cell line, RBL-2H3 (28), but previous attempts with human perforin did not lead to detectable production of the mature protein (27). Therefore, in an attempt to study perforin missense mutations associated with hemophagocytic lymphohistiocytosis (HLH), Voskoboinik and coworkers opted to introduce missense mutations into the mouse perforin cDNA sequence (29-31). However, interpretation of the results is complicated by 2 factors: first, 175 of 555 amino acid residues are different between the human and the mouse perforin sequence; second, the authors were unable to correlate changes in perforin detection with cytotoxicity (31).

In studies of FHLH2, over 50 mutations of the perforin gene (refs. 7-16, and unpublished results) have been identified. Most 
A
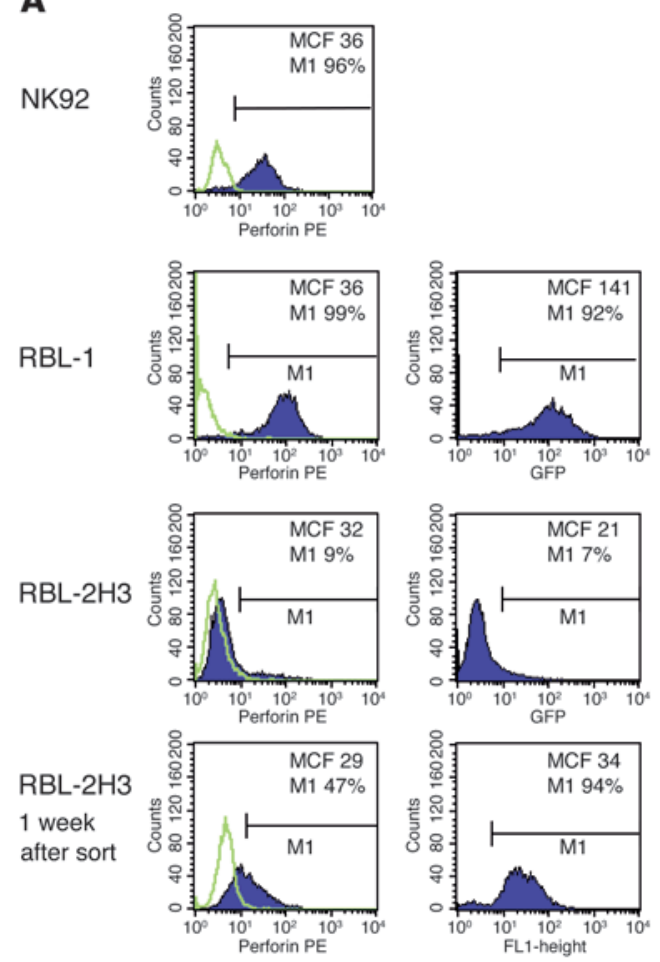

B
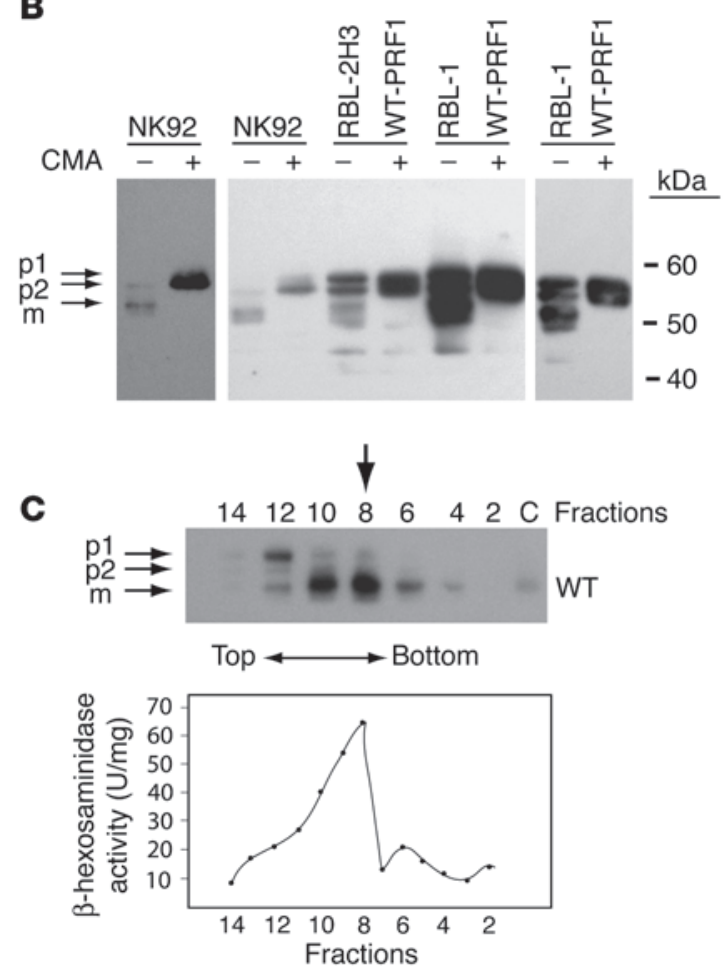

Figure 1

Expression of human perforin in RBL-1 and RBL-2H3 cells following retroviral transduction. (A) FC detection of WT human perforin and GFP in MIEG3-PRF1 virus-infected RBL-2H3 and RBL-1 cells 48 hours after infection. The sorted cells were a pool of 3 individual transfections. Perforin detection in NK92 cells is shown for comparison. The light green line represents the isotype control. (B) Detection of perforin in NK92 as well as in RBL-1 and RBL-2H3 transfectants by Western blotting following nonreducing SDS-PAGE. Precursor (p1 and p2) and mature (m) forms of perforin were visualized in all 3 cell lines by P1-8 antibody. Equivalent results were seen using H315 antibody. CMA was added to cultures overnight. Fifty micrograms of protein was loaded per lane. Since the endogenous perforin level in NK92 cells is lower than that in the transduced RBL-1 cells, a longer exposure is also shown. For transduced RBL-1 cells, a shorter exposure is also included to display the 2 precursor forms and 1 mature form of perforin. (C) Human perforin was detectable in the granular fraction of RBL-1 cells. RBL-1 cells were disrupted by nitrogen cavitation, and subcellular fractions were obtained after Percoll separation. Fractions 8-10, identified as granule fractions by the peak $\beta$-hexosaminidase activity, contained mature perforin ( $1.5 \mu \mathrm{g}$ protein per lane). "C" indicates a cell lysate from RBL-1 cells expressing WT human perforin ( $4 \mu \mathrm{g}$ protein).

of the perforin mutations in patients with FHLH2 do not lead to severe protein truncation but consist of amino acid substitutions. Several groups have analyzed mutant perforin by Western blot of PBMC lysates from individuals with missense mutations in PRF1 $(15,20,32,33)$. These studies have demonstrated levels of mature perforin protein ranging from absent to normal. However, studies of missense mutations from patient-derived cells and cell lines are limited by the infrequent occurrence of individuals with homozygous mutations. We sought to establish an in vitro system to answer a specific question: how do perforin missense mutations lead to absent perforin detection and impaired NK function? Here we report that, in contrast to previous studies, we were able to achieve expression of human perforin in both RBL-2H3 and RBL-1 cells. WT perforin was appropriately processed and stored in granules in both cell types. Perforin expressed in RBL-2H3 cells was functional in rbc lytic assays. RBL-1 cells possessed 10-fold higher levels of perforin than RBL-2H3 cells after retroviral transduction, allowing structural studies without cell sorting or selection.

Expression of 21 naturally occurring, perforin missense mutations in RBL-1 cells allowed us to directly analyze their impact on human perforin. Missense mutations were classified accord- ing to the presence of recognizable forms of precursor and mature perforin detected by immunoblots. These results show, for the first time to our knowledge, that the majority of missense mutations result in gross misfolding, incomplete maturation, and increased degradation of human perforin, interfering with the formation of mature active perforin.

\section{Results}

Recombinant buman perforin is stably expressed in RBL cells. Recombinant human perforin in MIEG3, a bicistronic retroviral vector containing GFP (34), was expressed after retroviral transduction in both RBL-2H3 and RBL- 1 cells. These 2 cell lines derive from the same rat mast cell tumor (35). RBL-2H3 cells have IgE receptors and undergo rapid degranulation upon binding of antigen to the receptor, while the RBL-1 cells do not efficiently degranulate under the same condition $(35,36)$. Previous studies have shown the utility of RBL- $2 \mathrm{H} 3$ cells for studying murine perforin function, but structural studies were lacking, presumably because of low-level expression of perforin (29-31).

Infection of RBL-2H3 cells with MIEG3-PRF1 retrovirus was achieved by preloading of viral supernatant onto fibronectin- 

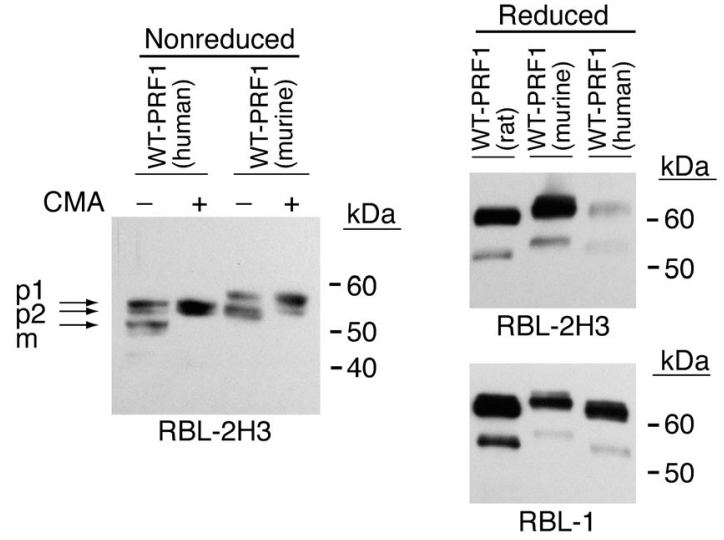

Figure 2

Detection of mouse perforin expressed in RBL cells. Mouse perforin CDNA was introduced into the MIEG3 viral vector, and RBL-1 and $\mathrm{RBL}-2 \mathrm{H} 3$ cells were infected with retrovirus. Mouse perforin expressed in both cells underwent a maturation process that could be blocked by CMA. However, under nonreducing and reducing conditions, mouse perforin had a slower mobility than human and rat perforin expressed in both cells. For RBL-2H3 cells, $100 \mu \mathrm{g}$ protein was loaded per lane, except for RBL-2H3 cells expressing rat perforin, which required only $10 \mu \mathrm{g}$ protein to detect perforin. For RBL-1 cells, $10 \mu \mathrm{g}$ protein was loaded per lane for all 3 cell lines. Detection was by P1-8 antibody.

coated plates prior to the addition of cells. Seven to twenty-five percent of the cells expressed GFP over 3 separate experiments as shown in a representative experiment in Figure 1A. To enrich for perforin-expressing cells, GFP-positive RBL-2H3 cells were sorted. Flow cytometry (FC) of cells after sorting revealed 94\% GFP-positive cells; however, the mean channel fluorescence (MCF) of perforin staining was 3 times lower than in RBL-1 cells expressing WT PRF1 cDNA (Figure 1A). In contrast, expression of GFP and perforin following retroviral infection of RBL-1 cells was highly efficient: GFP was expressed at high levels in $92 \%$ of viable cells, and WT perforin was expressed at high levels in $99 \%$ of viable RBL-1 cells. The levels of perforin in RBL-1 cells $(\mathrm{MCF}=95)$ were even higher than in NK92 cells $(\mathrm{MCF}=36)$, a human NK tumor cell line (Figure 1A). Human perforin levels in transduced RBL-1 cells were stable for many weeks (not shown).

Recombinant buman perforin undergoes proteolytic maturation in $R B L$ cells. Previous studies of perforin maturation in YT cells, an NK tumor cell line, revealed that perforin is translated as an inactive, precursor protein in the endoplasmic reticulum (27). The carboxyl terminal polypeptide is cleaved to form a functional mature protein during transit from the Golgi apparatus to cytoplasmic granules. Proteolytic processing can be interrupted by alkalinization of acidic compartments with concanamycin A (CMA) or by the serine/cysteine protease inhibitor leupeptin. As shown in Figure $1 \mathrm{~B}$, precursor and mature forms of perforin from NK92 cells migrate between 50 and $60 \mathrm{kDa}$ under nonreducing conditions. The mature band $(\mathrm{m})$ is not seen after treatment of NK92 cells overnight with CMA, while the precursor bands $\mathrm{p} 1$ and $\mathrm{p} 2$ are noted with increased intensity (Figure 1B). Both precursor forms of perforin migrate more slowly than the mature form.

We then analyzed whether the human WT perforin is appropriately processed in RBL-2H3 and RBL-1 cells after retroviral transduction of human PRF1 cDNA. As in NK92 cells, 3 bands were detectable, 2 precursor forms $(\mathrm{p} 1, \mathrm{p} 2)$ and a single mature form (m) of faster mobility (Figure 1B). CMA treatment overnight blocked the formation of the mature protein. Although perforin was readily detectable in RBL-2H3 cells by FC after sorting of cells, Western blot analysis required 10-20 times more protein from RBL-2H3 cell lysates than from RBL-1 lysates.

Human perforin is detected in the granules of transduced RBL-1 cells. Previous studies in human-derived YT cells showed the emergence of mature perforin only in dense lysosomal fractions (27). Subcellular fractionation of RBL-1 cells was performed to determine whether recombinant perforin was detectable in the dense granules of RBL-1 cells. Cells were disrupted by nitrogen cavitation, and lysates were fractionated on a preformed $48 \%$ Percoll gradient $(37,38)$. Eighteen fractions $(1.2 \mathrm{ml})$ were obtained, with fraction 1 obtained from the bottom of the gradient (most dense). Each fraction was assayed for $\beta$-hexosaminidase activity to locate the cytosolic granules (39), and perforin was detected by Western blot. As seen in Figure 1C, the majority of enzymatic activity associated with granule localization was seen in fractions 8-10. According to Western blot, perforin precursor bands were noted in fraction 12 , and the mature band was seen in fractions $8-10$. We conclude that recombinant human perforin was correctly processed and the mature form localized to the cytosolic granules.

Mouse perforin expressed in RBL cells has a different mobility on $S D S-P A G E$. Mouse perforin expressed in RBL-2H3 cells is functional in lytic assays and detectable in cytoplasmic granules (28). Therefore, we were surprised to see that mouse perforin expressed in RBL-1 and RBL-2H3 cells had a different banding pattern on immunoblot than human perforin (Figure 2). Two major bands corresponding to mouse perforin were detectable on nonreducing gels, and the precursor band was identified

\section{Figure 3}

Lytic function of perforin expressed in RBL-1 and RBL-2H3 cells. (A) Perforin-dependent ${ }^{51} \mathrm{Cr}$ release from TNP-treated rbcs coincubated for 4 hours with RBL cells, in the presence or absence (-IgE) of anti-2,4-dinitrophenol $\mathrm{IgE}$. Human and mouse perforin exhibited lytic activity after degranulation of RBL-2H3 cells. (B) In contrast, degranulation of RBL-1 cells expressing human perforin did not lead to rbc lysis. $E / T$, effector/target.
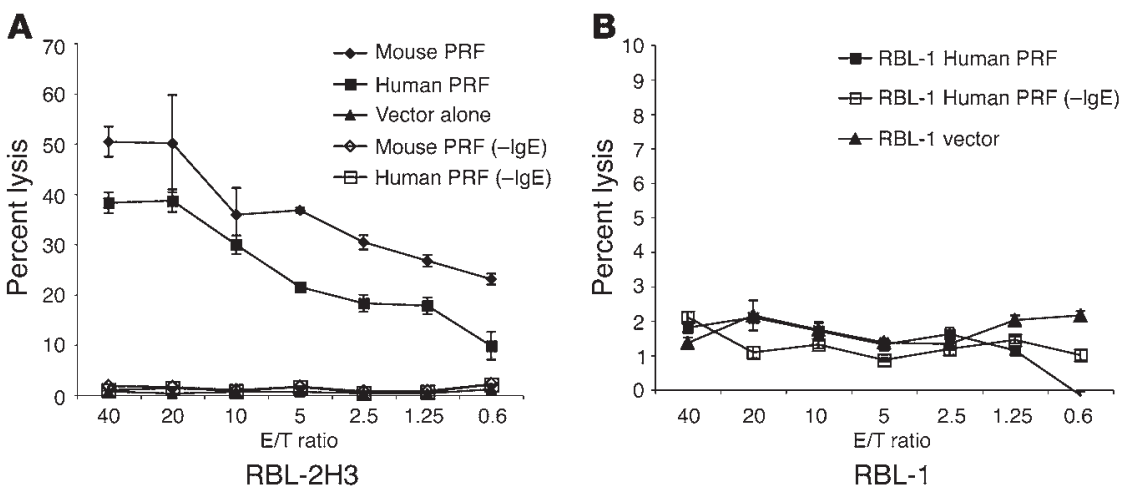
A

\section{B}

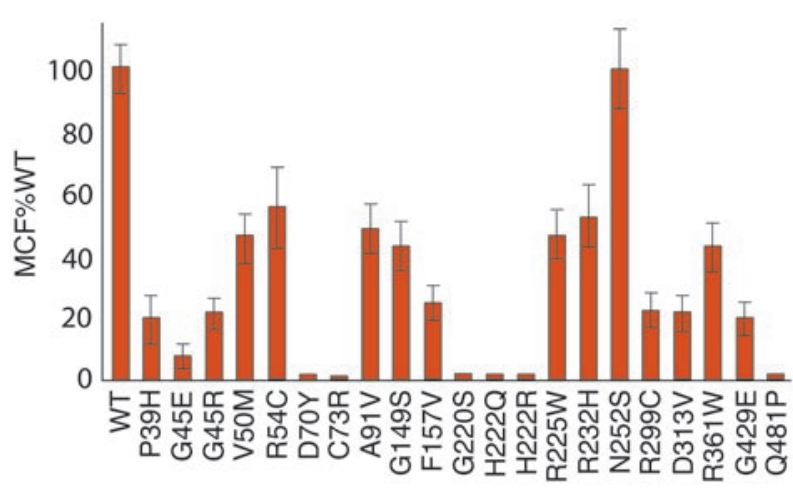

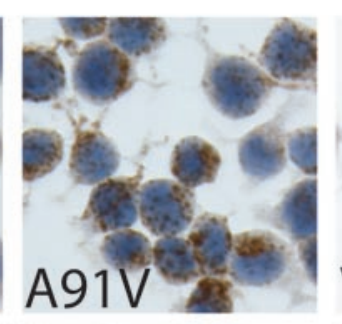
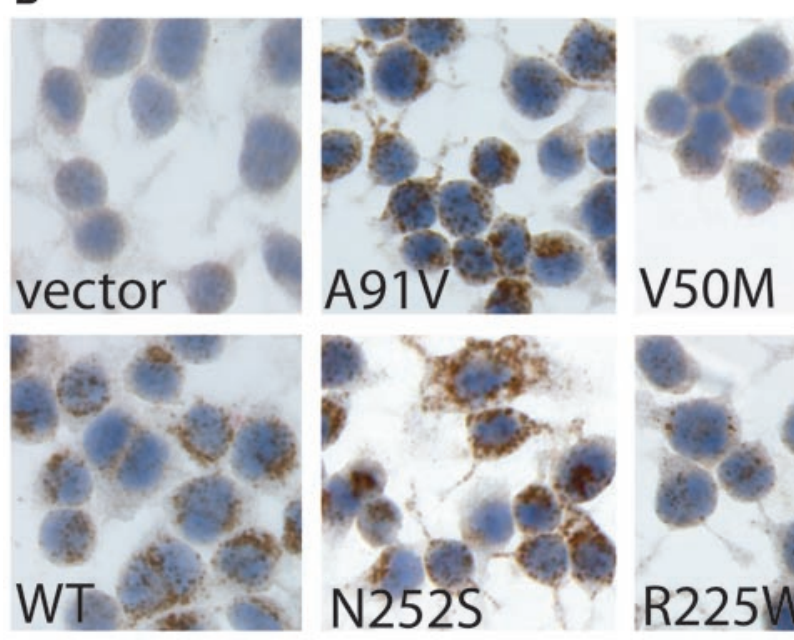

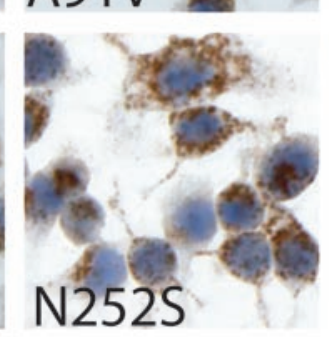

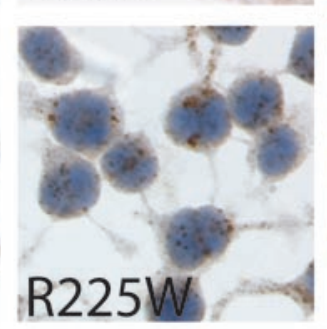
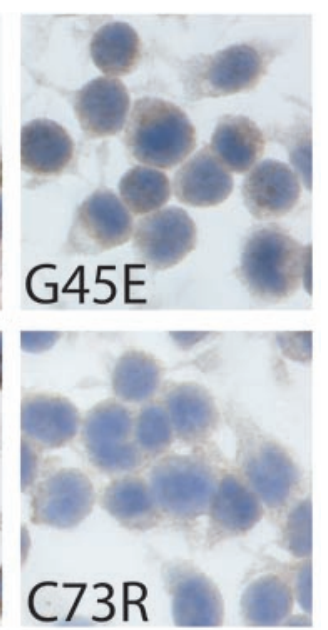

\section{Figure 4}

Expression of perforin with missense mutations in RBL-1 cells. (A) FC was performed after retroviral infection of RBL- 1 cells with PRF1 cDNA with and without missense mutations. Three independent experiments were performed. The perforin MCF for each mutant protein was normalized to WT and expressed as a percentage of WT perforin MCF (100\%). Error bars represent SEM. (B) Immunohistochemistry of perforin in RBL-1 cells expressing WT and mutant perforin proteins. RBL-1 cells were grown in slide chambers, and adherent cells were analyzed for perforin staining with the monoclonal ( $\delta G 9)$ anti-perforin antibody. Anti-mouse IgG coupled to HRP was used as a secondary antibody. The resulting stain is brown, whereas hematoxylin was used as a blue counterstain. Magnification, $\times 40$. by incubation overnight with CMA. However, the mobility of both forms was slower than that of human perforin equivalents under nonreducing and reducing conditions. This may have been due to altered glycosylation. The banding pattern of rat perforin was the same as that of the human. The level of expression of rat perforin was 10 -fold higher than that of human or mouse perforin in RBL-2H3 cells.

Human perforin expressed in $\mathrm{RBL}-2 \mathrm{H} 3$ cells exbibits lytic function. To confirm the lytic function of human WT perforin expressed in $\mathrm{RBL}$ cells, rbc lysis was assayed by ${ }^{51} \mathrm{Cr}$ release as described (28). Briefly, primary amines on human rbcs were modified by conjugation with a trinitrophenyl (TNP) group, and RBL cells were coated with anti-2,4-dinitrophenol (DNP) IgE that recognizes the TNP group. After a 4-hour coincubation, RBL-2H3 cells expressing human and mouse perforin exhibited lytic activity only in the presence of IgE-induced degranulation (Figure 3A). In contrast, no ${ }^{51} \mathrm{Cr}$ release was detectable in RBL-1 cells (Figure 3B). As RBL-1 cells had robust perforin expression, and protein maturation identical to that seen in RBL-2H3 cells, this cell line was suitable for analyzing the effect of perforin missense mutations on protein structure and maturation.

Expression of mutant perforins in transfected $R B L-1$ cells. To examine the effect of disease-associated mutations on the maturation of perforin, we introduced 21 different missense mutations into human perforin cDNA by site-directed mutagenesis and expressed them in RBL-1 cells. The mutations chosen were all reported as either compound heterozygous or homozygous alleles, were located throughout conserved and unique domains of the perforin molecule, and were seen in patients with FHLH2 and/or in individuals with other clinical phenotypes. Figure $4 \mathrm{~A}$ is a summary of the MCF of the 21 mutant perforins compared with WT perforin in RBL-1 cells from 3 independent experiments. As shown in Figure 4A, all but 1 mutant protein (PRF1-N252S) was detectable at a lower MCF than WT perforin. Detection of 14 mutants revealed diminished expression compared with that of WT perforin, and 6 mutants showed no expression by this method. This was not due to decreased RNA transcription, because high-level GFP expression was seen with all mutants, and no substantial variability of PRF1 mRNA levels was detectable by semiquantitative RT-PCR (data not shown). This suggests either that the mAb does not bind to the mutant proteins with the same avidity as to the WT protein or that the resulting perforin levels are lower secondary to aberrant processing and/or accelerated degradation of the protein.

Immunohistochemical staining of WT perforin expressed in RBL-1 cells appeared punctate secondary to storage in secretory granules (Figure 4B). As the antibody used in these experiments ( $\delta$ G9) was the same as that used in FC, the intensity of the immunohistochemical staining of WT and mutant perforin paralleled the FC data. For example, PRF1-G45E and PRF1-C73R were absent/low by FC and nondetectable by immunohistochemistry (Figure 4). PRF1-R225W, PRF1-V50M, and PRF1-A91V had an intermediate phenotype by FC, and staining by immunohistochemistry was punctate, like that of the WT perforin. PRF1-N252S was also indistinguishable from WT perforin by both methods. 


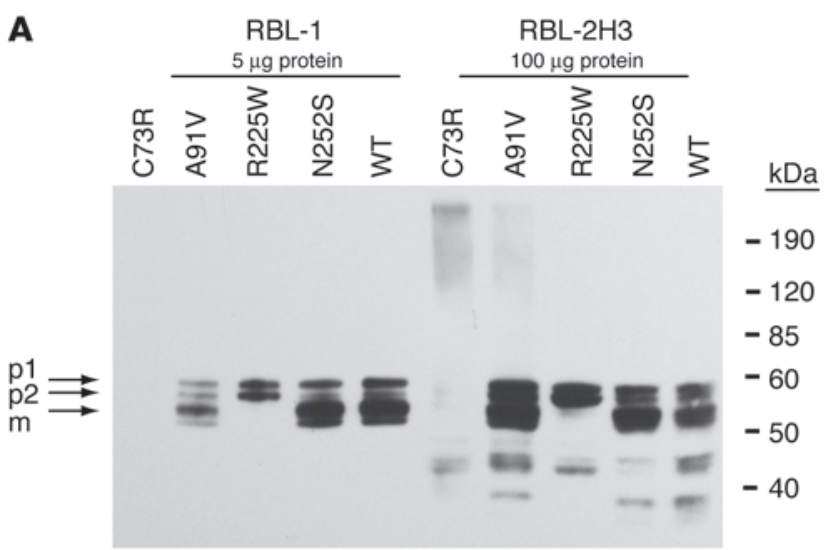

B

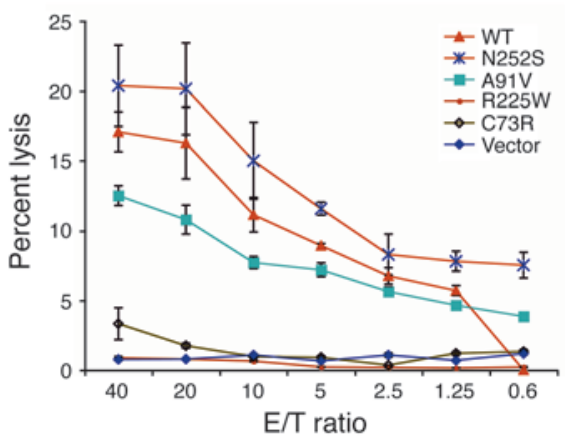

Impaired maturation of perforin can be assayed in $R B L-1$ and $R B L-2 H 3$ cells. The initial requirement for function of perforin is proper proteolytic processing of the precursor forms of the protein to the mature form. Previous studies have suggested that missense mutations of perforin may impair maturation. To examine the effect of the individual missense mutations on the maturation of perforin, we analyzed mutant perforin protein expressed in RBL-1 cells by nonreducing SDS-PAGE and Western blot (Figure 5A). The PRF1-N252S protein appeared like WT perforin, with 2 faintly detectable precursor bands (p1, p2) and a dominant band (m) representing the mature protein. Overnight CMA treatment of transduced RBL-1 cells resulted in the disappearance of the mature form (not shown). PRF1-A91V protein demonstrated an abnormal banding pattern, with 3 detectable bands as seen in WT perforin, but the mature form was not clearly dominant. A second pattern of abnormal perforin detection by immunoblotting was seen in PRF1-R225W. In contrast to WT perforin, PRF1-A91V, and PRF1-N252S, only 2 forms were detectable in PRF1-R225W transfectants, while the mature form was absent. Finally, distinct bands were barely detectable in mutant PRF1-C73R using either H315 or P1-8 antibody.

To assess whether the presence or absence of the mature form would predict lytic function, we expressed these same mutants in RBL-2H3 cells. After sorting for GFP-expressing cells, lysates were prepared for Western blot analysis. As seen in Figure 5A, the same banding patterns were seen in RBL-2H3 as were seen in RBL-1 cells; however, detection in RBL-2H3 cells required 10 times the amount of protein. The RBL-2H3 cells expressing mutant perforins were then tested for rbc lysis upon degranulation. As seen in Figure 5B, PRF1-N252S and PRF1-A91V expressed in RBL-2H3 cells demonstrated lytic activity against rbcs, while PRF1-R225W and PRF1-C73R had reduced lytic

\section{Figure 5}

Impaired maturation of perforin can be assayed in RBL-1 and RBL-2H3 cells. (A) Western blot analysis of perforin with missense mutations reveals 3 abnormal banding patterns. RBL- 1 cells expressing WT or mutant perforin protein were lysed in $2 \%$ NP- 40 , and lysates were run on SDS-PAGE under nonreducing conditions and probed with polyclonal antibody P1-8. PRF1-N252S exhibits the typical WT pattern with 2 faint precursor bands ( $p 1$ and $p 2$ ) and a more intense mature band $(\mathrm{m})$ with greater mobility. PRF1-C73R, PRF1-A91V, and PRF1-R225W exhibit abnormal banding patterns as explained in the text. Although the same banding patterns are noted in RBL-2H3 cells expressing WT or mutant perforin, detection required $100 \mu \mathrm{g}$ of protein. Detection was by P1-8 antibody. (B) Cytotoxic activity of human perforin bearing amino acid transitions of N252S, A91V, R225W, and $\mathrm{C} 73 \mathrm{R}$, expressed in RBL-2H3 cells. Perforin function was tested by its ability to lyse rbcs as described in Figure 3.

activity, indicating that the presence of the mature band predicted lytic function. In order to assess the generalizability of the results obtained from the RBL cell-based maturation assay for perforin, we analyzed the effect of 17 additional missense mutations on the proteolytic processing of perforin. Each mutant was categorized as belonging to 1 of 3 classes of mutant perforins with abnormal banding patterns (Figure 6).

Missense mutations with partial maturation of perforin (class 1). Three bands were detected on immunoblots of PRF1-G45R, PRF1-R54C, PRF1-A91V, PRF1-R232H, PRF1-R361W, and PRF1-G429E using H315 and P1-8 antibodies. To discern whether these forms represented precursor and mature protein, we analyzed the maturation of recombinant perforin after incubation overnight with CMA or a serine/cysteine protease

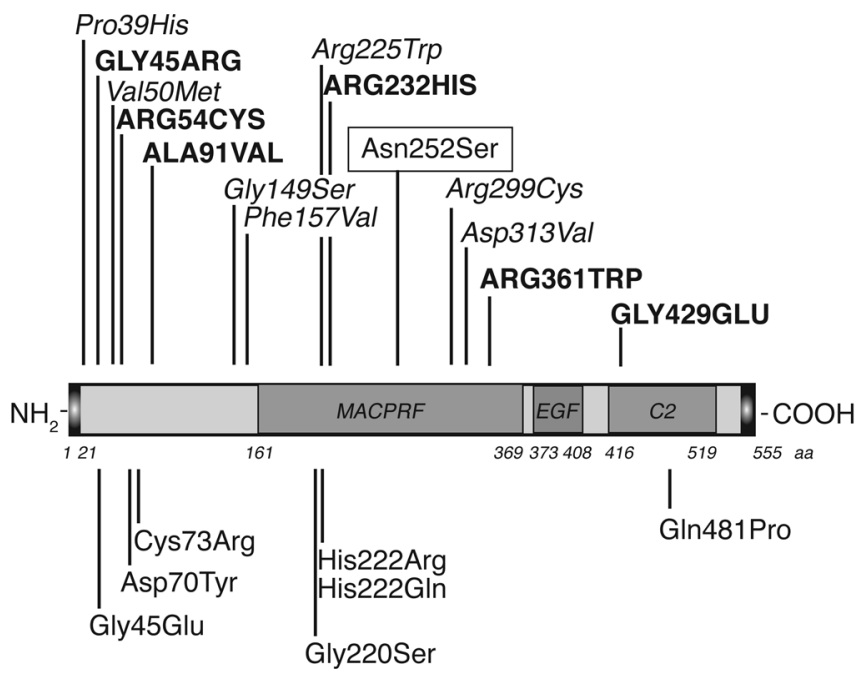

\section{Figure 6}

Schematic representation of the human perforin protein showing the location of amino acid transitions evaluated in the current study. The horizontal bar represents the perforin protein with its theoretical functional domains: the membrane attack complex domain (MACPRF), the EGF-like domain (EGF), and a domain homologous to the $\mathrm{C} 2$ domain of PKC (C2) $(27,42)$. The areas with gradient shading mark the signal peptide and the $\mathrm{C}$-terminal peptide, which are cleaved during maturation. Class 1: missense mutations with partial maturation of perforin (in bold capital letters above bar); class 2: no apparent maturation of perforin (in italics above bar); class 3: no recognizable forms of perforin (below the bar). PRF1-N252S (boxed) is a polymorphism. 


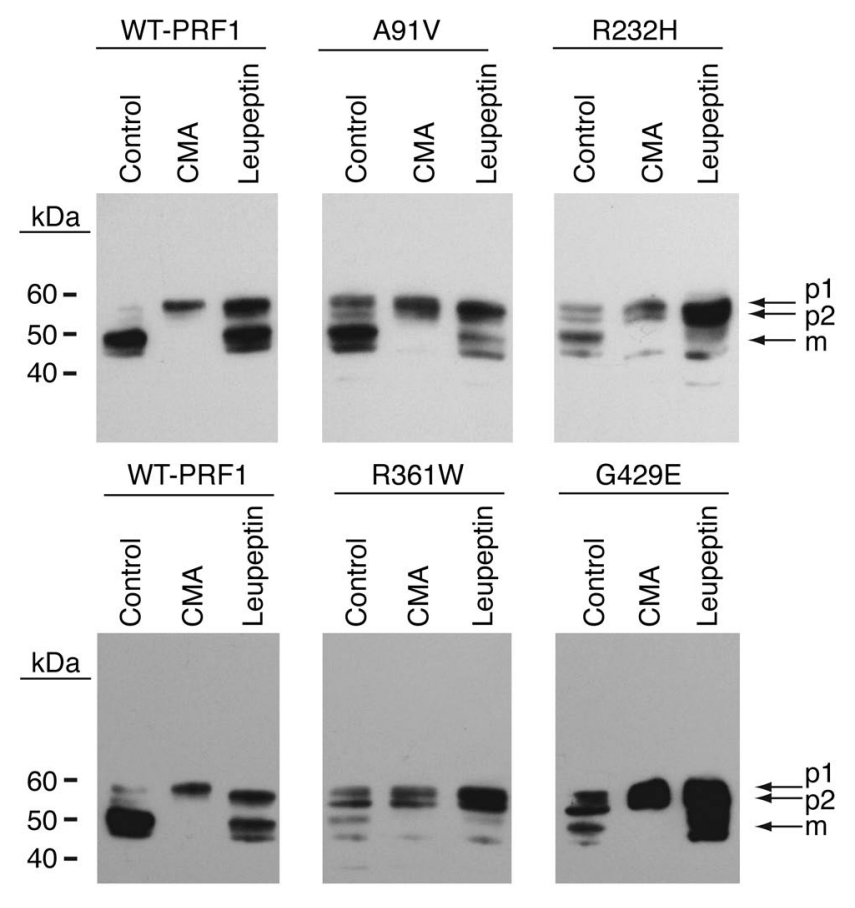

inhibitor, leupeptin. As presented in Figure 7, CMA treatment fully prevented production of the mature $(\mathrm{m})$ band of WT and mutant proteins, while leupeptin treatment resulted in only a partial block of proteolytic processing. Therefore, we were convinced that the bands visualized by immunoblot represented the 2 precursor and mature forms of perforin, with an increased intensity of precursor band staining.

Missense mutations with no apparent proteolytic maturation of perforin (class 2). Analysis of PRF1-P39H, PRF1-V50M, PRF1-G149S, PRF1-F157V, PRF1-R299C, and PRF1-D313V by nonreducing SDS-PAGE/Western blot showed the pattern characteristic for PRF1-R225W (Figure 8A). In contrast to class 1, only the precursor forms of perforin were detectable while the mature form was absent, suggesting that these missense mutations impair the proteolytic processing of the precursor proteins. Although it is possible that the mature form was produced but not detectable because of gross misfolding, use of 2 different antibodies for detection makes this a less likely explanation. Precursor bands from PRF1-V50M, PRF1-R299C, and PRF1-D313V were only visible after prolonged exposure of the gels. When class 2 mutations were analyzed by SDS-PAGE under reducing conditions, considerable degradation was apparent, as noted by the appearance of smaller bands at 50 and $40 \mathrm{kDa}$ representing degraded protein.

Immunohistochemical studies suggested that perforin protein with class 2 mutations was localized in the granules, as the signal was punctate like that of the WT perforin (Figure 4B). This was somewhat surprising, as we expected only mature perforin to be detectable in granules. To further analyze the intracellular distribution of mutant perforin, cell extracts from RBL-1 cells expressing WT, PRF1-V50M, and PRF1-R225W were fractionated over Percoll gradients. Samples from fractions were subjected to nonreducing SDS-PAGE, followed by immunoblot. As seen in Figure $8 \mathrm{~B}$, the mature band of WT perforin was readily detectable in fractions 8-10. However, PRF1-V50M and PRF1-R225W showed precursor bands localized to these same fractions, with-

\section{Figure 7}

Western blot analysis of RBL-1 expressing PRF1 missense mutations with reduced processing to the mature form. The maturation of perforin was interrupted by alkalinization of acidic compartments with CMA or by inhibition of proteolysis by leupeptin overnight. Under nonreducing SDS-PAGE conditions, immunoblotting (H315 antibody) revealed that mutant proteins (PRF1-A91V, -R232H, -R361W, and -G429E) appeared to have a maturation pattern comparable to that of WT perforin, despite reduced intensity of the mature band: CMA completely blocked processing to the mature band, while leupeptin blocked it only partially. Twenty micrograms protein was loaded per lane, except for the WT perforin, of which $10 \mu \mathrm{g}$ was loaded because of the strength of the signal.

out mature forms noted. We conclude that the precursor forms were indeed transported to the granules, and proteolytic processing was arrested.

Missense mutations with no recognizable forms ofperforin (class 3). The precursor and mature forms of perforin were barely detectable or absent in mutants PRF1-G45E, PRF1-D70Y, PRF1-C73R, PRF1-G220S, PRF1-H222Q, PRF1-H222R, and PRF1-Q481P after nonreducing SDS-PAGE and detection with H315 antibody as shown in Figure 9. Although 3 bands were visualized after a longer exposure time for PRF1-G45E, PRF1-D70Y, and PRF1-Q481P with P1-8 antibody, they were not precursor and mature forms, as the treatment with CMA did not cause a disappearance of the fast-migrating band (not shown).

The failure to detect precursor and mature forms of perforin in RBL-1 cells under nonreducing conditions did not arise because of a lack of protein expression, since mutant proteins in this class were readily visualized by Western blot after denaturation of the protein lysates (Figure 9). This result indicated that perforin was synthesized, but protein misfolding prevented recognition by 3 antibodies in the nondenatured state. When denatured, these mutant proteins exhibited intense staining of smaller bands representing degraded protein (Figure 9).

Further evidence for protein misfolding of class 3 mutations is suggested by the detection of large aggregates on SDS-PAGE under nonreducing conditions (Figure 9). These aggregates were also detectable by Western blot of some missense mutations in classes 1 and 2, although at reduced intensity (not shown). Reduction and boiling of lysates prior to electrophoresis led to the elimination of aggregates and to the appearance of smallmolecular weight species likely representing degraded perforin protein. These high-mobility bands were not seen on nonreducing gels. Therefore it is likely that the slowly migrating bands at the top of the nonreducing gels represent aggregates of degraded perforin protein.

Expression level of mutant perforins in RBL-1 cells mimics that in human NK cells. We examined whether the expression levels of mutant perforins in RBL-1 cells were comparable to those seen in patient NK cells (Table 1). In order to evaluate the contribution of a single allele in human NK cells, we first chose individuals heterozygous for 50delT and a missense mutation on the second allele (G45E/50delT, C73R/50delT, and Q481P/50delT). The 50delT mutation creates a premature stop codon and leads to a severe truncation with no detectable perforin in patients homozygous for 50delT (14). Therefore, in the NK cells, the only detectable perforin is derived from the allele with the missense mutation. PRF1-G45E, PRF1-C73R, and PRF1-Q481P are all 


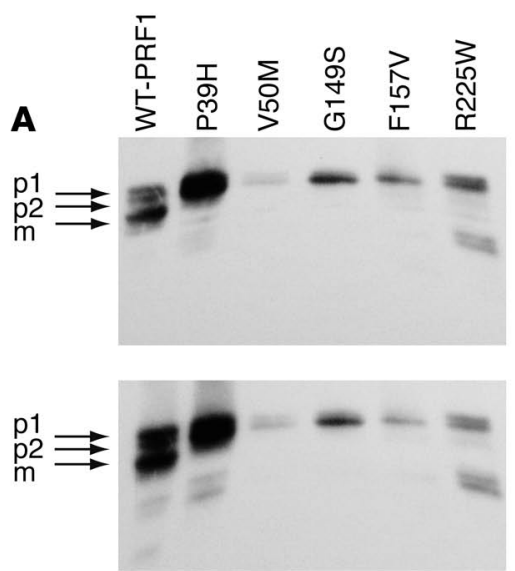

Nonreduced
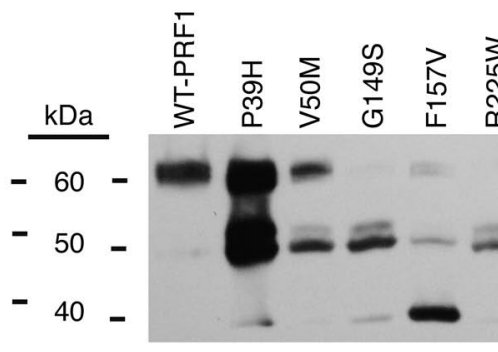

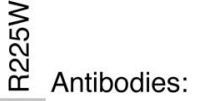

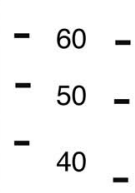

40

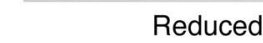

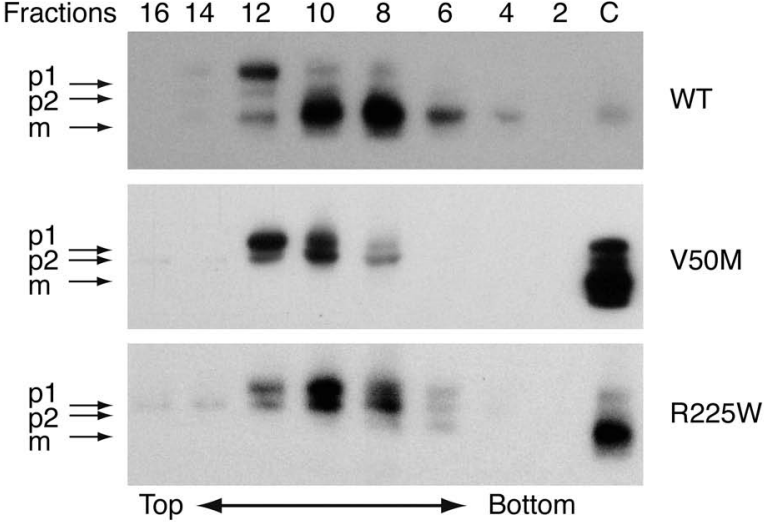

\section{Figure 8}

Western blot analysis of RBL-1 expressing PRF1 missense mutations with absent mature band formation. (A) Mutant proteins demonstrated an absence of the mature band by nonreducing SDS-PAGE followed by Western blot using antibodies as labeled. WT perforin is shown for comparison. The use of 2 different antibodies (H315 and $\mathrm{P} 1-8$ ) was critical to demonstrate the presence of the $70-\mathrm{kDa}$ band under reducing conditions for PRF1-F157V and PRF1-R225W. Fifty micrograms protein was loaded per lane. (B) RBL-1 cells expressing WT, V50M, and $\mathrm{R} 225 \mathrm{~W}$ perforin were disrupted and fractionated through Percoll gradients. Samples from every second fraction of the gradients were then analyzed for the presence of precursor and mature forms of perforin on nonreducing SDS-PAGE. WT perforin is shown for comparison. "C" indicates a cell lysate from RBL-1 cells expressing WT human perforin (4 $\mu \mathrm{g}$ protein). For PRF1-V50M, $4 \mu \mathrm{g}$ protein was loaded per lane; $1.5 \mu \mathrm{g}$ was loaded for WT PRF1 and PRF1-R225W. Detection was by $\mathrm{P} 1-8$ antibody. class 3 mutations: no recognizable precursor or mature forms of perforin are detectable by immunoblot. Similarly, the expression of these alleles was associated with an absence of perforin detection by FC in both transduced RBL-1 cells and patient NK cells. Second, we examined the level of perforin expression in NK cells from patients homozygous for missense mutations V50M, G149S, and R225W. These class 2 mutations had no mature band formation as detected by immunoblot. By FC, intermediate perforin levels were observed in NK cells from patients and in transduced RBL-1 cells. Finally, we compared expression levels of a class 1 allele, A91V, between RBL-1 and NK cells. Perforin detection in NK cells from a patient with HLH and a healthy individual homozygous for the $\mathrm{A} 91 \mathrm{~V}$ allele revealed reduced MCF. Reduced perforin was also detected in RBL-1 cells expressing recombinant PRF1-A91V; however, the reduction in MCF was more pronounced when this allele was expressed in NK cells. In summary, these results show that expression levels of mutant perforin in RBL-1 cells correlated with data from human NK cells when analyzed by FC with the same antibody ( $\delta G 9)$.

Classification predicts age of disease onset. Table 2 shows the age of disease onset and NK function of patients reported with FHLH2 and bearing 9 different missense mutations analyzed in this report. Individuals were chosen if they were homozygous for the missense mutation or if the second PRF1 allele carried a nonsense mutation leading to a severe protein truncation. Class 3 mutations were associated with an age of onset less than 1 year and absent NK function. In contrast, half of the individuals with class 2 mutations had a disease onset in early childhood (age 2-7 years) with impaired NK function. The NK function of a patient with homozygous V50M mutations varied between normal and very low depending on the time of assay. A91V is the only mutation from class 1 reported in homozygotes or heterozygotes with protein deletions, and in these patients onset was later in childhood or in adulthood.

In order to investigate the impact of additional class 1 mutations, we examined patients who were compound heterozygotes (Table 3). In general, children with class 1 mutations had an age of disease onset not earlier than the first year of life, supporting the relationship between the classification of mutations and age of onset. It is remarkable that whenever the A91V allele was present, the disease onset was always beyond infancy (between the ages of 3 and 22 years).

\section{Discussion}

To our knowledge, this is the first report of expression of human perforin at sufficient levels for structural analysis in a mammalian cell line. Retroviral transduction of RBL-1 cells was highly efficient, perforin expression was stable, and analysis required no cell sorting. The level of perforin produced by RBL-1 transfectants exceeded the level present in NK92 cells and was amenable to Western blot analysis. Proteolytic maturation of recombinant perforin in RBL-1 and RBL-2H3 cells, like the maturation of endogenous 


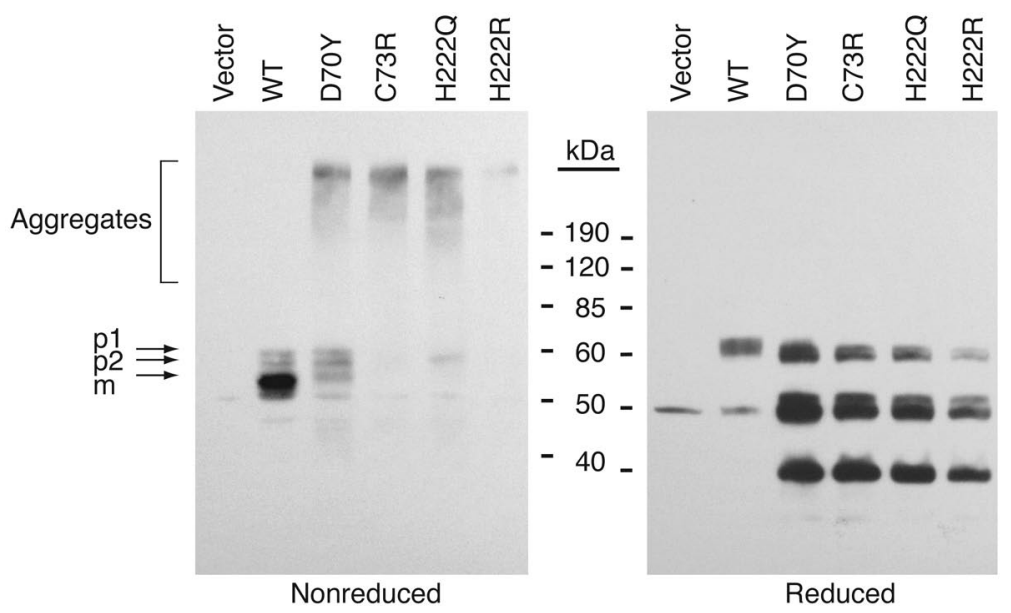

Figure 9

Western blot analysis of RBL-1 expressing PRF1 missense mutations with an absence of the characteristic precursor and mature bands. Under reducing conditions, mutant perforins were not readily visualized by nonreducing SDS-PAGE and Western blot. When these same samples were denatured/boiled in 2-mercaptoethanol, it became apparent that perforin protein was present but not recognized in the native state. These mutations demonstrated high-intensity degraded bands not seen in lysates from RBL-1 cells expressing WT perforin. In addition, each lane has high-molecular weight aggregates detectable with the perforin antibody. Aggregate formation (marked by a bracket) of perforin was eliminated by boiling of the samples in the presence of 2-mercaptoethanol (reduced) before electrophoresis. All lanes were loaded with $50 \mu \mathrm{g}$ protein. Detection was by H315 antibody.

perforin in NK92 cells, occurred in acidic compartments and was partially blocked by a serine/cysteine protease inhibitor, leupeptin, and completely blocked by CMA. Expression of perforin by retroviral transduction in RBL-2H3 lines was less efficient than in RBL-1 cells and required sorting of the cells by FC to enrich for perforin-expressing cells. The parallel use of the 2 cell lines in this study allowed both structural and functional analysis of perforin amino acid substitutions.

Analysis of missense mutations within the context of human perforin is advantageous for many reasons. First, the expression of human perforin was detectable by FC, allowing direct comparison with studies of human NK cells in patients. Second, we have shown that mouse perforin expressed in RBL cells has a different mobility on reducing and nonreducing SDS-PAGE than endogenous perforin from NK92 cells or human perforin expressed in RBL cells. Finally, results from this study of human perforin mutations in RBL-1 cells differ from those reported in studies of perforin mutations introduced into the mouse cDNA expressed in RBL-2H3 cells (29-31). Voskoboinik et al. reported severely decreased protein detectable on immunoblots for mouse perforin with mutations corresponding to human P39H and D70Y (31). In the current study, PRF1-P39H and PRF1-D70Y were readily detectable in RBL-1 cells under the same conditions (Figure 8A, panel: P1-8/reduced; and Figure 9, panel: reduced). Other mutations cited as absent or severely decreased when introduced into mouse perforin but readily detected in the current study include PRF1G45E, PRF1-G45R, PRF1-G220S, PRF1-R232H, PRF1-R361W, and PRF1-Q481P (Supplemental Figure 1; supplemental material available online with this article; doi:10.1172/JCI26217DS1). In addition, when Voskoboinik et al. analyzed the R225W transition in mouse perforin, they only saw diffuse cytoplasmic staining with the P1-8 antibody, and minimal full-length protein was noted on Western blot (29). In contrast, human PRF1R225W showed the characteristic punctate appearance consistent with packaging in the secretory granules of RBL-1 cells, and full-length protein was detectable by SDS-PAGE followed by immunoblotting (Figure 8B). Therefore, we suggest caution in the interpretation of studies of perforin missense mutations introduced into mouse perforin.

Perforin is synthesized as an inactive precursor and must undergo proteolytic processing to achieve the active form of the protein (27). Therefore, classification of missense mutations of perforin is most informative according to the presence of recognizable forms of precursor and mature protein. Perforin mutations classified by class 3 are by far the most abnormal when compared with WT perforin by all measures. There is evidence of gross protein misfolding, protein degradation, and lack of lytic function. Patients with these mutations have an early age of onset, nondetectable perforin protein, and impaired NK function (Tables 1 and 2).

Class 2 mutations are distinguished by the presence of precursor bands and the absence of mature band formation after expression in RBL-1 cells. Although one might expect these mutations to be associated with early onset of disease and absent NK function, the clinical phenotype was most variable in this group (Table 2). The localization of precursor perforin protein with class 2 mutations to the granules of RBL-1 cells suggests one possible explanation: precursor protein may also be transported to the granules of NK cells and may exhibit residual function in individuals with class 2 perforin mutations. Although PRF1-R225W expressed in RBL-2H3 cells did not exhibit lytic activity against rbcs in the current study, this assay may not be sensitive enough to detect low-level lytic function.

From the current study it is apparent that class 1 perforin mutations demonstrate partial proteolytic maturation (G45R, R54C, A91V, R232H, R361W, and G429E). These mutations are described

\section{Table 1}

Comparison of perforin missense alleles in patient NK cells and RBL- 1 cells

\begin{tabular}{lccc}
\multicolumn{2}{c}{ Patient NK cells } & \multicolumn{2}{c}{ RBL-1 cells } \\
Genotype & Perforin MCF & Allele & Perforin MCFA \\
C73R/50delT & $-B$ & C73R & - \\
Q481P/50delT & - & Q481P & - \\
G45E/50delT & - & G45E & 3.7 \\
V50M/V50M & 44 & V50M & 41 \\
G149S/G149SC & - & G149S & 53 \\
G149S/G149S & 45 & & \\
G149S/G149SC & 63 & & \\
R225W/R225W & 75 & R225W & 77 \\
R225W/R225W & 29 & & \\
A91V/A91V & 61 & A91V & 87 \\
A91V/A91VD & 37 & & \\
WT controls & $373 \pm 129 E$ & WT & $130 \pm 4$ \\
\hline
\end{tabular}

AData from a representative experiment. WT was transfected in triplicate $(\mathrm{MCF} \pm \mathrm{SEM}) .{ }^{\mathrm{B}}-$, not detectable. CIndividuals also have N252S polymorphism. DParent of a child with $\mathrm{HLH}$. EMCF $\pm 95 \%$ confidence interval. 


\section{Table 2}

Comparison of classification and clinical phenotype ${ }^{A}$

$\begin{array}{lccccc}\text { Class }^{B} & \text { Allele 1 } & \text { Allele 2 } & \text { Age of onset } & \text { NK functionC } & \text { Reference } \\ 3 & \text { G45E } & \text { 50delT } & 8 \mathrm{mo} & <0.01 & 14 \\ 3 & \text { C73R } & \text { 50delT } & 4 \mathrm{mo} & <0.01 & 14 \\ 3 & \text { G220S } & \text { G220S } & 1.5 \mathrm{mo} & \text { Absent } & 8 \\ 3 & \text { G220S } & 50 \text { delT } & 2 \mathrm{mo} & \text { D } & 10 \\ 3 & \text { Q481P } & \text { 50delT } & 2 \mathrm{mo} & <0.01 & 14 \\ 2 & \text { V50M } & \text { V50M } & 7 \mathrm{yr} & 9.2,0.01 \mathrm{E} & 14 \\ 2 & \text { V50M } & \text { Y219stop } & 4 \mathrm{mo} & \text { D } & 9 \\ 2 & \text { G149SF } & \text { G149S } & 6 \mathrm{mo} & <0.01 & 14 \\ 2 & \text { G149SF } & \text { G149S } & 8 \mathrm{mo} & 0.6 & G \\ 2 & \text { G149SF } & \text { G149S } & 12 \mathrm{mo} & \text { D } & \text { G } \\ 2 & \text { R225W } & \text { R225W } & 2 \mathrm{yr} & <0.01 & 14 \\ 2 & \text { R225W } & \text { R225W } & 5 \mathrm{yr} & 0.1 & 14 \\ 2 & \text { R225W } & \text { S150stop } & 5 \mathrm{yr} & <0.01 & 14 \\ 1 & \text { A91V } & \text { A91V } & 5 \mathrm{yr} & <0.01 & G \\ 1 & \text { A91V } & \text { W374stop } & 4.9 \mathrm{yr} & \text { Absent } & 32 \\ 1 & \text { A91VH } & \text { W374stop } & 22 \mathrm{yr} & \text { Absent } & 18 \\ 1 & \text { A91VH } & \text { W374stop } & 21 \mathrm{yr} & \text { Absent } & 18\end{array}$

AIncludes individuals who are homozygous or heterozygous for a nonsense mutation leading to protein truncation. BPatterns recognizable by Western blot: class 1, missense mutations with partial maturation; class 2 , no apparent maturation; or class 3 , no recognizable forms of perforin.

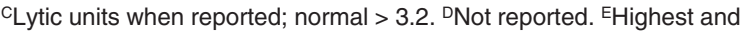
lowest values for patient. FCarries N252S polymorphism. GPreviously unpublished. HIndividuals are siblings.

in patients diagnosed with FHLH2 older than 1 year, suggesting they may be "milder" mutations with reduced but detectable perforin and NK function. The A91V transition is the most commonly reported class 1 mutation and is associated with disease onset beyond the toddler years. Other investigators have noted this amino acid transition in children and adults with lymphoma, in children with leukemia, or in healthy individuals (21-23). The $\mathrm{R} 232 \mathrm{H}$ transition has been described in 2 heterozygous individuals with HLH, but siblings of these 2 patients have remained healthy into the teen years despite the same genotype $(10,19)$. In studies of $\mathrm{A} 91 \mathrm{~V}$ and $\mathrm{R} 232 \mathrm{H}$ substitutions in the mouse perforin sequence, both substitutions were associated with reduced, but not absent, function as determined by the ability to lyse Jurkat cells $(29,31)$. Therefore, the A91V and R232H transitions appear to be disease associated, with incomplete penetrance. In contrast to patients with $\mathrm{A} 91 \mathrm{~V}$ and $\mathrm{R} 232 \mathrm{H}$, siblings with another class 1 mutation, G429E, had disease onset during the second year of life $(7,10)$. Voskoboinik et al. introduced this mutation into the mouse cDNA, expressed it in RBL-2H3 cells, and noted reduced cytotoxicity (29). A second paper from this group suggests that the neighboring aspartate is critical for maintaining perforin function and that the G429E transition interferes with calcium binding (30). The present study suggests an additional mechanism for decreased cytotoxicity: impaired proteolytic processing to the mature protein.

In contrast to the other "milder" mutations described above, expression of PRF1-N252S in RBL-1 cells was indistinguishable from expression of WT perforin, suggesting proper folding and maturation. Lytic studies in RBL-2H3 cells expressing PRF1-N252S show that its function is comparable to WT. Although initial reports described PRF1-N252S as a disease-causing mutation in FHLH2 (7), subsequent studies revealed that this protein is expressed in healthy individuals as a benign polymorphism $(14,40)$. The N252 residue is not conserved in perforin among species, nor between perforin and C7, C8, and C9. The combination of biochemical and epidemiologic studies makes it highly unlikely that PRF1-N252S plays a role as a pathogenic mutation in FHLH2.

In summary, we have presented data, for the first time to our knowledge, on the effect of missense mutations on the maturation process of human perforin. These studies in RBL cells expressing human perforin provide a basis for understanding the impact of missense mutations on the structure of the protein. The precise mechanism by which the various missense mutations lead to impaired proteolytic processing of perforin remains to be established. Nevertheless, the information produced by our analysis of human perforin mutations reveals that mutations with partial proteolytic maturation often present with a "milder" phenotype, associated with residual perforin detection and NK function, older age at onset of disease, and a more diverse clinical phenotype, while absence of the mature, functional perforin predicts absent NK function and early onset of FHLH2.

\section{Methods}

Cell culture. All cells were obtained from American Type Culture Collection. RBL-1 and RBL-2H3 cells were maintained in RBL MEM with Earle's salts supplemented with L-glutamine, $1 \mathrm{mM}$ sodium pyruvate, $100 \mu \mathrm{M}$ nonessential amino acids, and 15\% FBS. NK92 cells were maintained in $\alpha$-MEM with $12.5 \%$ horse serum, $12.5 \%$ FBS, and supplemented with $20 \mu \mathrm{M}$ folate, $200 \mu \mathrm{M}$ inositol, and $200 \mathrm{U} / \mathrm{ml}$ recombinant IL-2. Phoenix-Eco cells for retroviral transduction were obtained with permission from Gary Nolan (Stanford University Medical Center, Stanford, California, USA) and maintained in DMEM with 10\% FBS. For metabolic studies, $100 \mathrm{ng} / \mathrm{ml} \mathrm{CMA} \mathrm{or} 100 \mu \mathrm{g} / \mathrm{ml}$ leupeptin was added to cultures of $5 \times 10^{6}$ cells for overnight incubation.

Generation of retroviral vectors and expression in RBL cells. Human perforin cDNA was amplified from MOLT-4 QUICK-Clone cDNA (BD Biosciences - Clontech) and cloned into the pCR4-Topo vector (Invitrogen Corp.). Mutations were introduced using the QuikChange Site-Directed Mutagenesis Kit (Stratagene), and the resulting clones were sequenced in their entirety. The cDNA was then transferred into the mouse retroviral vector MIEG3, which allows expression of the gene of interest in cis with the cDNA encoding the enhanced GFP (34). Mouse perforin cDNA was amplified from FVB/N splenic cDNA and further cloned as above. The retroviral vector was transfected into Phoenix-Eco by calcium phosphate, and the viral supernatants were collected from 24 to 48 hours after transfection. The supernatants were applied to RBL cells every

Table 3

Compound heterozygous patients with class 1 mutations

\begin{tabular}{|c|c|c|c|c|}
\hline Allele 1 & Allele 2 & $\begin{array}{c}\text { Age of } \\
\text { onset }\end{array}$ & $\begin{array}{c}\text { NK } \\
\text { function }\end{array}$ & Reference \\
\hline A91V & G45R/R54C (class 1) & $3 \mathrm{yr}$ & 0.1 & 12 \\
\hline A91V & A91V/R232H (class 1) & $13 \mathrm{yr}$ & Reduced & 19 \\
\hline $\mathrm{R} 232 \mathrm{H}$ & WT & $27 \mathrm{mo}$ & $B$ & 10 \\
\hline R361W & G149SC (class 2) & $4 \mathrm{yr}$ & $<0.01$ & 14 \\
\hline G429ED & R225W (class 2) ${ }^{\mathrm{D}}$ & $17 \mathrm{mo}$ & B & 7,10 \\
\hline G429ED & R225W (class 2) & $28 \mathrm{mo}$ & B & 7,10 \\
\hline G429ED & R225W (class 2) ${ }^{\mathrm{D}}$ & $14 \mathrm{mo}$ & B & 7,10 \\
\hline
\end{tabular}

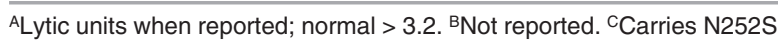
polymorphisms. DIndividuals are siblings. 
24 hours for 48 hours. For the first RBL-2H3 infection, fibronectin plates were incubated for 2 hours with viral supernatant before cells were added. FC was performed 48-96 hours after the final infection.

Flow cytometry. Cells were fixed/permeabilized with IntraPrep (BD) and stained with either PE-conjugated anti-perforin ( $\delta G 9$; BD Biosciences Pharmingen) or the respective isotype-matched control for 20 minutes at room temperature. After washing, cells were resuspended in $1 \%$ paraformaldehyde and analyzed on a FACSCalibur flow cytometer (BD Biosciences).

Immunohistochemistry. Adherent RBL-1 cells were grown on slides for 2 days, then rinsed with PBS and fixed with 95\% ethanol. Automated staining was performed by Dako Autostainer using a monoclonal anti-perforin antibody ( $\delta G 9$; Pierce); an anti-human, biotin-conjugated antibody; streptavidin-coupled HRP (Dako); and 3,3'-diaminobenzidine-4HCl (DAB) substrate. Background staining was done with hematoxylin.

Western blot. Cell lysates were prepared using a 2\% NP-40 lysis buffer (27). Samples were run on $10 \%$ polyacrylamide gels using Laemmli sample buffer with or without $5 \% 2$-mercaptoethanol or $350 \mathrm{mM} \mathrm{DTT}$ and boiled. Equal amounts of protein were loaded in each lane, except where indicated. Actin staining of reduced gels revealed no evidence of nonspecific proteolysis and confirmed equal loading (data not shown). Western blotting was performed with a polyclonal rabbit antibody, H315, against human perforin, amino acids 241-555 (Santa Cruz Biotechnology Inc.), or a monoclonal rat antibody, P1-8 (41), against mouse perforin, amino acids 209-380 (gift of H. Yagita, Juntendo University School of Medicine, Tokyo, Japan). HRP-conjugated secondary antibodies were used for ECL.

Subcellular fractionation. RBL-1 cells were disrupted by nitrogen cavitation, and subcellular fractions were prepared by the method of Borregaard et al. as previously described $(37,38)$ with the following modifications: $0.5 \times 10^{8}$ to $1 \times 10^{8}$ cells were disrupted by nitrogen cavitation. A $48 \%$ Percoll gradient was prepared and centrifuged at $39,000 \mathrm{~g}$ for 10 minutes, and then samples were loaded and centrifuged for 45 minutes at 39,000 $\mathrm{g}$. The Percoll beads were not removed prior to Western blot or enzymatic assays. Fifty-microliter aliquots of each fraction were assayed for $\beta$-hexosaminidase activity as previously described by Shiver et al. (39). The results were normalized to the protein content of each granule fraction $(\mathrm{U} / \mathrm{mg}$ protein). Western blot was performed as above. Samples contained a constant amount of protein in Laemmli buffer and were not denatured.

$R B C$ lytic assays. RBL cells were coated with anti-2,4-dinitrophenol IgE (Sigma-Aldrich) at $5 \mu \mathrm{g} / \mathrm{ml}$ for 15 minutes, $37^{\circ} \mathrm{C}$, in growth media. After washing 3 times with RPMI-1640, the cells were resuspended at $4 \times 10^{6}$ per milliliter. Target rbcs were loaded with ${ }^{51} \mathrm{Cr}$, as previously described (28). They were then modified by trinitrophenylation and incubated with $10 \mathrm{mM}$ picryl sulfonic acid in PBS, pH 7.4, for 15 minutes at $37^{\circ} \mathrm{C}$. Cells were washed 3 times, then resuspended in RPMI with $20 \%$ pooled human serum. Various effector/target ratios were coincubated in quadruplicate, in round-bottom, 96 -well plates for 4 hours. ${ }^{51} \mathrm{Cr}$ release into the supernatant was measured and the percentage lysis calculated as follows: (cpm of sample - cpm of background)/(cpm of maximum - cpm of background).

NK function. Assessment of NK function was performed as previously described using chromium release from K562 target cells and serial dilutions of PBMCs for effector cells (14).

Patients. Individuals were studied with approval by the Cincinnati Children's Hospital Medical Center Institutional Review Board. Appropriate informed consent, when required, was obtained. The individuals were diagnosed and treated at a variety of institutions, and blood samples were sent to Cincinnati Children's Hospital Medical Center for perforin staining and assessment of NK function. DNA sequencing of PRF1 was performed at this institution as well. The diagnosis of HLH was made based on a constellation of symptoms including hepatomegaly, splenomegaly, leucopenia, thrombocytopenia, anemia, hypofibrinogenemia, hypertriglyceridemia, CNS involvement, and/or fever. Diagnosis was confirmed by contact with the referring physician.

\section{Acknowledgments}

This work was supported by the March of Dimes, grant 6-FY01-64, and grants from the Histiocytosis Association of America and Canada. Funding for K.A. Risma was provided by NIH-NRSA T32, grant HD43005-02, and a Federation of Clinical Immunology Societies/Millennium Postdoctoral Fellowship Award. MIEG3 was a gift from David Williams. We appreciate the help provided by Yi $\mathrm{Gu}$ in establishing retroviral transductions and by Pierre Henkart in establishing lytic assays of rbcs.

Received for publication July 11, 2005, and accepted in revised form October 18, 2005.

Address correspondence to: Janos Sumegi, Division of Hematology/Oncology, Cincinnati Children's Hospital Medical Center, 3333 Burnet Avenue, Cincinnati, Ohio 45229, USA. Phone: (513) 636-5976; Fax: (513) 636-3549; E-mail: Janos.Sumegi@cchmc.org.
1. Russell, J.H., and Ley, T.J. 2002. Lymphocyte-mediated cytotoxicity. Annu. Rev. Immunol. 20:323-370.

2. Kagi, D., et al. 1994. Cytotoxicity mediated by $\mathrm{T}$ cells and natural killer cells is greatly impaired in perforin-deficient mice. Nature. 369:31-37.

3. Walsh, C.M., et al. 1994. Immune function in mice lacking the perforin gene. Proc. Natl. Acad. Sci.U.S. A. 91:10854-10858.

4. Binder, D., et al. 1998. Aplastic anemia rescued by exhaustion of cytokine-secreting CD8+ T cells in persistent infection with lymphocytic choriomeningitis virus. J. Exp. Med. 187:1903-1920.

5. Matloubian, M., et al. 1999. A role for perforin in downregulating T-cell responses during chronic viral infection. J. Virol. 73:2527-2536.

6. Jordan, M.B., Hildeman, D., Kappler, J., and Marrack, P. 2004. An animal model of hemophagocytic lymphohistiocytosis (HLH): CD8+ T cells and interferon gamma are essential for the disorder. Blood. 104:735-743

7. Stepp, S.E., et al. 1999. Perforin gene defects in familial hemophagocytic lymphohistiocytosis. Science. 286:1957-1959.

8. Clementi, R., et al. 2001. Six novel mutations in the PRF1 gene in children with haemophagocytic lymphohistiocytosis. J. Med. Genet. 38:643-646.

9. Goransdotter Ericson, K., et al. 2001. Spectrum of perforin gene mutations in familial hemophagocytic lymphohistiocytosis. Am. J. Hum. Genet. 68:590-597.

10. Feldmann, J., et al. 2002. Functional consequences of Perforin gene mutations in 22 patients with familial haemophagocytic lymphohistiocytosis. Br. J. Haematol. 117:965-972.

11. Suga, N., et al. 2002. Perforin defects of primary haemophagocytic lymphohistiocytosis in Japan. Br. J. Haematol. 116:346-349.

12. Kogawa, K., et al. 2002. Perforin expression in cytotoxic lymphocytes from patients with hemophagocytic lymphohistiocytosis and their family members. Blood. 99:61-66.

13. Ueda, I., et al. 2003. Characteristic perforin gene mutations of haemophagocytic lymphohistiocytosis patients in Japan. Br. J. Haematol. 121:503-510.

14. Molleran Lee, S., et al. 2004. Characterization of diverse PRF1 mutations leading to decreased natural killer cell activity in North American families with hemophagocytic lymphohistiocytosis. J. Med. Genet. 41:137-144.

15. Ishii, E., et al. 2005. Genetic subtypes of familial hemophagocytic lymphohistiocytosis: correlations with clinical features and cytotoxic T lymphocyte/ natural killer cell functions. Blood. 105:3442-3448.

16. Imashuku, S., et al. 2005. Occurrence of haemophagocytic lymphohistiocytosis at less than 1 year of age: analysis of 96 patients. Eur. J. Pediatr. 164:315-319.

17. Henter, J.I., et al. 2002. Treatment of hemophagocytic lymphohistiocytosis with HLH-94 immunochemotherapy and bone marrow transplantation. Blood. 100:2367-2373.

18. Clementi, R., et al. 2002. Adult onset and atypical presentation of hemophagocytic lymphohistiocytosis in siblings carrying PRF1 mutations. Blood. 100:2266-2267.

19. Busiello, R., et al. 2004. Atypical features of familial hemophagocytic lymphohistiocytosis. Blood. 103:4610-4612

20. Katano, H., et al. 2004. Chronic active Epstein-Barr virus infection associated with mutations in perforin that impair its maturation. Blood. 103:1244-1252.

21. Clementi, R., et al. 2005. A proportion of patients with lymphoma may harbor mutations of the perforin gene. Blood. 105:4424-4428.

22. Santoro, A., et al. 2005. A single amino acid change A91V in perforin: a novel, frequent predisposing 
factor to childhood acute lymphoblastic leukemia? Haematologica. 90:697-698.

23. Zur Stadt, U., et al. 2004. A91V is a polymorphism in the perforin gene not causative of the FHLH phenotype. Blood. 105:4700-4706.

24. Podack, E.R., and Konisgberg, P.J. 1984. Cytolytic T cell granules: isolation, structural, biochemical, and functional characterization. J. Exp. Med. 160:695-710

25. Henkart, P.A., Millard, P.J., Reynolds, C.W., and Henkart, M.P. 1984. Cytolytic activity of purified cytoplasmic granules from cytotoxic rat large granular lymphocyte tumors. J. Exp. Med. 160:75-93.

26. Thia, K.Y., Smyth M.J., and Trapani, J.A. 1993. Expression of human perforin in a mouse cytotoxic $\mathrm{T}$ lymphocyte cell line: evidence for perturbation of granule-mediated cytotoxicity. J. Lenkoc. Biol. 54:528-533.

27. Uellner, R, et al. 1997. Perforin is activated by a proteolytic cleavage during biosynthesis which reveals a phospholipid-binding $\mathrm{C} 2$ domain. EMBO J. 16:7287-7296.

28. Shiver, J.W., and Henkart, P.A. 1991. A non-cytotoxic mast cell tumor line exhibits potent IgEdependent cytotoxicity after transfection with the cytolysin/perforin gene. Cell. 64:1175-1181.

29. Voskoboinik, I., et al. 2004. The functional basis for hemophagocytic lymphohistiocytosis in a patient with co-inherited missense mutations in the perforin (PFN1) gene. J. Exp. Med. 200:811-816.

30. Voskoboinik, I., et al. 2005. Calcium-dependent plasma membrane binding and cell lysis by perforin are mediated through its $\mathrm{C} 2$ domain. A critical role for aspartate residues $429,435,483$, and 485 but not 491. J. Biol. Chem. 280:8426-8434.

31. Voskoboinik, I., Thia, M.C., and Trapani, J.A. 2005. A functional analysis of the putative polymorphisms A91V and N252S, and 22 missense perforin mutations associated with familial hemophagocytic lymphohistiocytosis. Blood. 105:4700-4706.

32. Trambas, C., et al. 2005. A single amino acid change, A91V, leads to conformational changes which can impair processing to the active form of perforin. Blood. 106:932-937.

33. Feldmann, J., et al. 2005. Severe and progressive encephalitis as a presenting manifestation of a novel missense perforin mutation and impaired cytolytic activity. Blood. 105:2658-2663.

34. Williams, D.A., et al. 2001. Dominant negative mutation of the hematopoietic-specific Rho GTPase, Rac2, is associated with a human phagocyte immunodeficiency. Blood. 96:1646-1664.

35. Barsumian, E.L., Isersky, C., Petrino, M.G., and Siraganian, R.P. 1981. IgE-induced histamine release from rat basophilic leukemia cell lines: isolation of releasing and nonreleasing clones. Eur. J. Immunol.
11:317-323.

36. Gao, Y., Hansson, M., Calafat, J., Tapper, H., and Olsson, I. 2004. Sorting soluble tumor necrosis factor (TNF) receptor for storage and regulated secretion in hematopoietic cells. J. Leukoc. Biol. 76:876-885.

37. Borregaard, N., Heiple, J.M., Simons, E.R., and Clark, R.A. 1983. Subcellular localization of the b-cytochrome component of the human neutrophil microbicidal oxidase: translocation during activation. J. Cell Biol. 97:52-61.

38. Davis, J.E., Sutton, V.R., Browne, K.A., and Trapani, J.A. 2003. Purification of natural killer cell cytotoxic granules for assaying target cell apoptosis. J. Immunol. Methods. 276:59-68.

39. Shiver, J.W., Su, L., and Henkart, P.A. 1992. Cytotoxicity with target DNA breakdown by rat basophilic leukemia cells expressing both cytolysin and granzyme A. Cell. 71:315-322.

40. Rieux-Laucat, F., Le Deist, F., and De Saint Basile, G. 2005. Autoimmune lymphoproliferative syndrome and perforin. N. Engl. J. Med. 352:306-307.

41. Kawasaki, A., et al. 1990. Perforin, a pore-forming protein detectable by monoclonal antibodies, is a functional marker for killer cells. Int. Immunol. 2:677-684.

42. Lichtenheld, M.G., et al. 1988. Structure and function of human perforin. Nature. 335:448-451. 